\title{
Bioclimatic architecture as the main part of green building
}

\author{
Michael Eichner ${ }^{1}$ and Zinaida Ivanova ${ }^{2, *}$ \\ ${ }^{1}$ German University in Cairo - GUC, New Cairo City, Egypt \\ ${ }^{2}$ Moscow State University of Civil Engineering, Yaroslavskoye shosse, 26, Moscow, 129337, Russia
}

\begin{abstract}
Studies of the relationship between environmental quality of buildings, urban living conditions and the global climate change are becoming more relevant today, since living conditions in numerous megacities are rapidly deteriorating, and the climate change with economic and social impact endangering economies of whole nations. Deeper understanding of the climate saving quality of buildings and, in particular, their live cycle balance of included GHG emissions will allow architects and decision makers in the construction sector to properly take into account relevant environmental, climatic, and human factors, to create favorable ecological and healthy urban environments and habitat conditions. Architect M. Eichner, one of the authors of the article, developed urban projects for the North African desert area of Luxor as well as for the cold climate area of St. Petersburg with building designs considering the local climate, economic conditions, and best available construction solutions, evaluating and comparing their environmental impact on the biosphere and global climate. Conclusion of the authors: The local and global environmental impact of commonly constructed buildings through material, water, and energy consumption differs significantly between the different countries. Buildings for residential use with common and best-available solutions for construction, material and heating technology do not meet minimum climate saving requirements in accordance with international standards.
\end{abstract}

\section{Introduction}

Today, the negative impact of buildings on our local environment and global climate, as well as on the health and productivity of building users, are severe problems. The significant increase of extreme weather events requires new efforts and methods of all stakeholders in the building sector. The authors research the environmental impact of commonly constructed single family housing building typologies in different climatic regions on the global climate by calculating and comparing the Global Warming Potential (GWPG) in [kg CO2-Äqu./(m2NRF a)], the relationship of renewable and non-renewable energy of primary energy consumption (PEe,G / PEges, G) of buildings and amounts of main environmental harmful emission types (ODP, POCP, AP, EP). The very long life-

\footnotetext{
${ }^{*}$ Corresponding author: ivanovazi@mail.ru
} 
cycles of buildings, calculated up to 50 years according to international sustainable certification systems like the DGNB system, create risks of energy use 'lock-in' with the effect of low ambition for climate saving enhancement of buildings and cities for decades, freezing high levels of harmful emissions on a large scale. Using state-of-the-art sustainable standards immediately, for both new and retrofitted buildings, would alleviate this hazard [1]. To gain a deeper understanding of climate implications of building typologies and to evaluate the impact of buildings on the biosphere, the authors prepared a Live-CycleCalculations of single housing buildings, planned according commonly used construction principles and material solutions in different climatic region to quantify the $\mathrm{CO} 2$ reduction gap for housing buildings to low-emission standards.

The rise in greenhouse gas emission dates back into the beginning of the industrialization of the 19th century, but only in the years from 1971 to 2004, the carbon dioxide emissions (CO2) grew $1.7 \%$ per year in the residential sector. A research executed by the authors shows that despite widespread knowledge about energy saving and retrofitting technologies in the building sector, open accessible environmental data of building materials, well known sustainable building certification labels, an average housing building constructed in an developed country like Germany or Austria as well as average buildings in less developed countries like Russia or Egypt exceed several times recommended levels of greenhouse emissions $(\mathrm{CO} 2)$ and other harmful environmental emissions (CFC1, C2H4, SO2, PO4).

\section{Research aim and methodology}

Climate saving architecture includes research and consideration of climatic factors like use of natural light and solar radiation, humidity, precipitation, wind speed but not less important is the evaluation of environmental impacts of buildings on ground water, soil, local temperature and air quality. As environmental impacts of any built structures are mainly depending on materials and types of energy utilized in buildings (renewable, nonrenewable), only a live cycle assessment (LCA-assessment), can provide significant and detailed information of the environmental friendliness of buildings and their level of climate saving quality. The formation of architectural objects and building structures, their composition, constructive and material solutions should be based on an environmental impact assessment, allowing the optimization of buildings and cities during the planningand construction process to determine amounts of harmful emissions caused during their entire live cycle, defined usually with 50 years.

According to the German sustainable housing certification system (NaWoh) for low rise complexes in central Europe, a maximum of $\leq 12 \mathrm{~kg} \mathrm{CO} 2-\ddot{A q u} /\left(\mathrm{m} 2 \mathrm{NRF}^{*} \mathrm{a}\right)$ is recommended as acceptable value of yearly $\mathrm{CO} 2$ greenhouse gas emissions per square meter gross floor area, which is an amount usually several times exceeded in buildings worldwide. As reference for the following presented building research the NaWoh system and its benchmarks, defined in NaWoh 3.1 - Eco-balance for emission-related environmental impacts [2], were chosen to test the level of harmful emission, created by buildings, which can be considered as commonly planned and constructed (Table 1). This emission balancing according building typologies and common construction practice allows extrapolating the level of environmental impact of construction sectors as a whole for certain countries, based on reliable market share reports. 


\begin{tabular}{|c|c|c|c|}
\hline & Stufe & Wert & Einheit \\
\hline \multirow[t]{3}{*}{ Ozonschichtabbaupotenzial ODP } & akzeptabel & $2,0^{*} 10^{-6}$ & $\mathrm{~kg}$ CFC11-Äqu. / (m² NRF"a) \\
\hline & gut & $1,0^{*} 10^{-6}$ & kg CFC11-Äqu. I (m² $\left.{ }^{2}{ }^{*}{ }^{*} \mathrm{a}\right)$ \\
\hline & sehr gut & $7,0^{\star} 10^{-}$ & $\mathrm{kg}$ CFC11-Äqu. $/\left(\mathrm{m}^{2} \mathrm{NRF}^{*} \mathrm{a}\right)$ \\
\hline \multirow[t]{3}{*}{ Ozonbildungspotenzial POCP } & akzeptabel & 0,014 & $\mathrm{~kg} \mathrm{C}_{2} \mathrm{H}_{4}-\ddot{A} q u . /\left(\mathrm{m}^{2}{ }_{\text {NRF }}{ }^{*} \mathrm{a}\right)$ \\
\hline & gut & 0,01 & $\mathrm{~kg} \mathrm{C}_{2} \mathrm{H}_{4}$-Aqu. / ( $\left.\mathrm{m}^{2}{ }_{\text {NRF }}{ }^{*} \mathrm{a}\right)$ \\
\hline & sehr gut & 0,007 & $\mathrm{~kg} \mathrm{C}_{2} \mathrm{H}_{4}-\mathrm{A} q u . /\left(\mathrm{m}^{2}{ }_{\text {NRF }}{ }^{*} \mathrm{a}\right)$ \\
\hline \multirow[t]{3}{*}{ Versauerungspotenzial AP } & akzeptabel & 0,07 & $\mathrm{~kg} \mathrm{SO}_{2}-\mathrm{Aqu} . /\left(\mathrm{m}^{2}{ }_{\mathrm{NRF}}{ }^{*} \mathrm{a}\right)$ \\
\hline & gut & 0,05 & $\mathrm{~kg} \mathrm{SO}_{2}$-Äqu. I $\left(\mathrm{m}^{2}{ }_{\mathrm{NRF}}{ }^{*} \mathrm{a}\right)$ \\
\hline & sehr gut & 0,035 & $\mathrm{~kg} \mathrm{SO}_{2}-\mathrm{Aqu} . /\left(\mathrm{m}_{\mathrm{NRF}}^{2}{ }^{*} \mathrm{a}\right)$ \\
\hline \multirow[t]{3}{*}{ Überdüngungspotenzial EP } & akzeptabel & 0,007 & $\mathrm{~kg} \mathrm{PO}_{4}-\mathrm{A} q u . /\left(\mathrm{m}_{\mathrm{NRF}}^{2}{ }^{*} \mathrm{a}\right)$ \\
\hline & gut & 0,005 & $\mathrm{~kg} \mathrm{PO}_{4}-\mathrm{Aqu} . /\left(\mathrm{m}^{2}{ }_{\mathrm{NRF}}{ }^{*} \mathrm{a}\right)$ \\
\hline & sehr gut & 0,0035 & $\mathrm{~kg} \mathrm{PO}_{4}-\mathrm{Aqu} . /\left(\mathrm{m}^{2} \mathrm{NRF}^{*} \mathrm{a}\right.$ \\
\hline
\end{tabular}

Fig. 1. NaWoh 3.2.1. LCA impact categories for housing.

The robustness of the environmental data and emission balances of evaluated building examples was guaranteed by the use of the available online eLCA calculator of the Federal Institute for Research on Building, Urban Affairs and Spatial Development (BBSR) of the German government. The emission balance approaches reflect different metrics (renewable energy, primary energy, carbon emissions, CFC1, C2H4, SO2, PO4 emission), balance boundaries (materials and technologies used in buildings) and weighting systems (benchmark system of the DGNB or NaWoh system) while the building examples covered various single family houses with common construction typologies, energy supply options and best available materials for different climatic zones. The evaluation was created by using a beta version of the so-called "eLCA bauteileditor" with calculated energy and construction material data from three well documented energy-efficient single housing buildings. The tool mainly allows checking and quantifying live cycle GHG emissions balances according building construction components and energy categories.

\section{Literature Review}

Climate-protective or, in other words, bioclimatic architecture is based on the minimization of peculiarities of the regional climate on the buildings and in return of the impact of buildings on the local environment and global climate. It uses a wide range of principles in a holistic manner and can be defined as buildings and structures that provide comfortable and healthy conditions for the existence of a person in a building (natural microclimate), with minimal energy consumption and minimizing harmful emissions, industrial wastes and vital activity to the environment [3]. The German sustainable certification system DGNB for buildings and urban districts requires consideration and balancing according benchmarks of following aspects, which can be considered directly relating to climate saving and the protection of human urban environments the biosphere in general:

Nearly zero energy building design assumes design and construction with maximum use of natural light and minimization of the use of energy for heating or cooling of buildings throughout the entire year. Today there are different levels of energy-efficient buildings, like the KFW 60 and KFW 40 building standard, the Passive house standard, Zero Emission Standards or Active House Standard, with buildings erected in German and Switzerland and many other countries. Wide application has only found the KFW 60 and KFW 40 building standard, as they are financially subsidized in Germany by the German state. Although KFW 60 and KFW 40 are only considered as energy efficiency standards, they are directly linked to climate friendliness, since reduced energy consumption also means reduced greenhouse gas emissions. 
Building construction with a high living and environmental quality requires considering the specific potentials and risks of its location and nearby context including respecting the Biosphere, surrounding nature, landscape and climate. Respecting the biosphere implies that architects, developer and building owners do not exploit the biosphere, but respect the humanitarian balance of the biotechnosphere. The humanitarian balance of the biotechnosphere is a system of equations that establishes quantitative normative relationships between: a) the life potential of the biosphere, the population and the number of places to meet the needs of the population in the regions; $b$ ) the needs of people, the technosphere, the resources of the biosphere and the ability of the biosphere of the regions to meet these needs. This balance has a direct relationship to architectural objects as part of the technosphere. Quantitative calculations of these balances allow rational preservation and development of the biosphere [4].

A case study on bioclimatic architecture, prepared by D.L.Jones, investigating 44 architectural objects around the world, constructed in accordance with "green building" principles and his monograph "Architecture and the Environment: Bioclimatic Building Design" with data on building energy characteristics and environmental hygiene [5] was used as references for this research. Another very detailed research project, related to the end of the twentieth century, prepared by B. Givoni, "Climatic Considerations in Building and Urban Design" gives an up-to-date overview of construction and urban climatology [6]. Enhanced study activities of this issue began with the adoption of the UN Sustainable Development Program in 1992. The first comprehensive guide for architects and designers on principles of sustainable architecture was prepared by M. J. Crosbie, "Green Architecture. A Guide to Sustainable Design" [7] with design strategies, including orientation optimization of buildings, maximization of daylight use in buildings, energysaving lighting and heating, intelligent HVAC control systems, natural ventilation and thermal insulation of buildings. The work also presents a selection of examples of environmental sensitive buildings and structures.

New environmental research is characterized by methods analyzing the interaction of buildings and the biosphere, such as environmental impact assessment and cost-benefit analysis, developing topics related to the design of energy-saving facilities, energy regulation and conservation of resources, and the problems of sustainable design for various types of buildings $[8,9]$. Today, high attention is paid to the problem of renewable resource and materials, energy saving through the use of intelligent technologies. Buildings and facilities in cities are the main energy consumers, accounting for 30 to 40 percent of consumption in general, and 70 percent of total electricity consumption and create up to 50 percent of all harmful emissions. Studies related to the processes of global warming like in the article of Razin A.D., Alhalabi Z.Sh. provide an overview and comparison of possible architectural solutions using bioclimatic solutions, which can mitigate the negative side effects of global warming [10].

\section{Research}

During the research, three single family houses were undergoing detailed evaluation of their climate saving and environmental quality. "Low emission architecture" mostly involves the use of the sun as the main source of light and heat energy. For example, the architecture of southern Europe has traditionally been based on the principles of reasonable use of sunlight and heat like the "Atica" project of the company Velux, encompassing special operating systems managing the inside climate by automatically opening and closing windows, blinds, shutters and roller blinds, turning the cooling and heating systems on and off according to the set parameters for temperature, humidity, daytime or season, and also a wide range of low emission construction materials. 


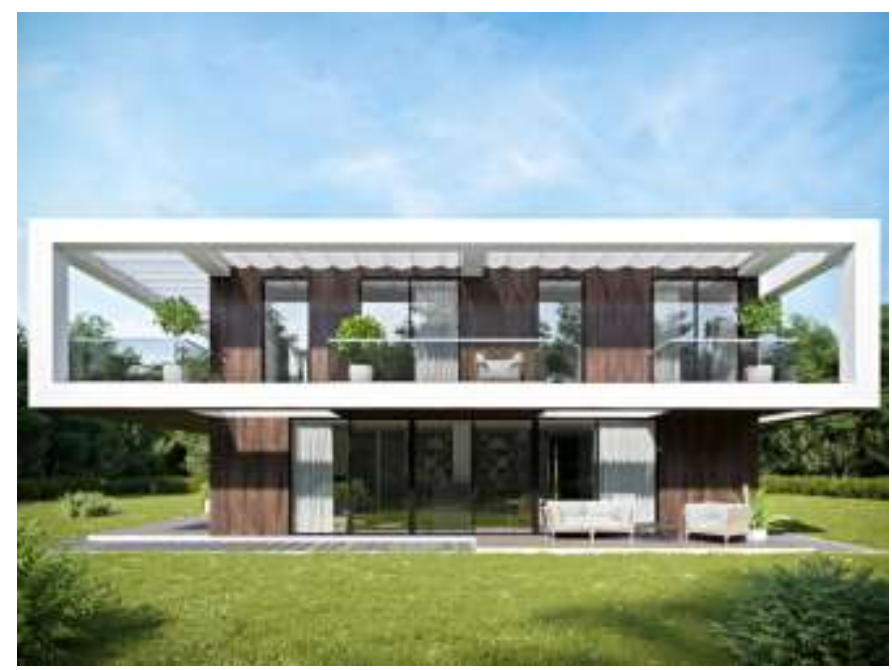

Fig. 2. Environmental Skin Home, Prof. M. Eichner, 2016.

One of the buildings analyzed by the was the environmental Skin Home, a building design by Prof. M. Eichner, which uses a transformable skin, allowing adaption to harsh weather conditions in northern areas of Russia, reduce energy-loss, protection from strong winds, reflect sunlight and improve living quality for inhabitants (Fig.2). With the compact and climate adaptive building design and the use of a common wooden frame system as its main construction material, it was considered to be a contribution to climate-friendly architecture.

Another building tested by the authors on their environmental impact is a standardized single family home with 214 sq. gross floor area, produced and constructed in prefabricated wooden-frame wall and slab elements, a system common in central and eastern Europe, counting for a share of $16 \%$ in the sale of building product in the domestic construction market in Germany [11], thus counting for a significant share of national climate gas and environmental harmful emissions (Fig. 3).

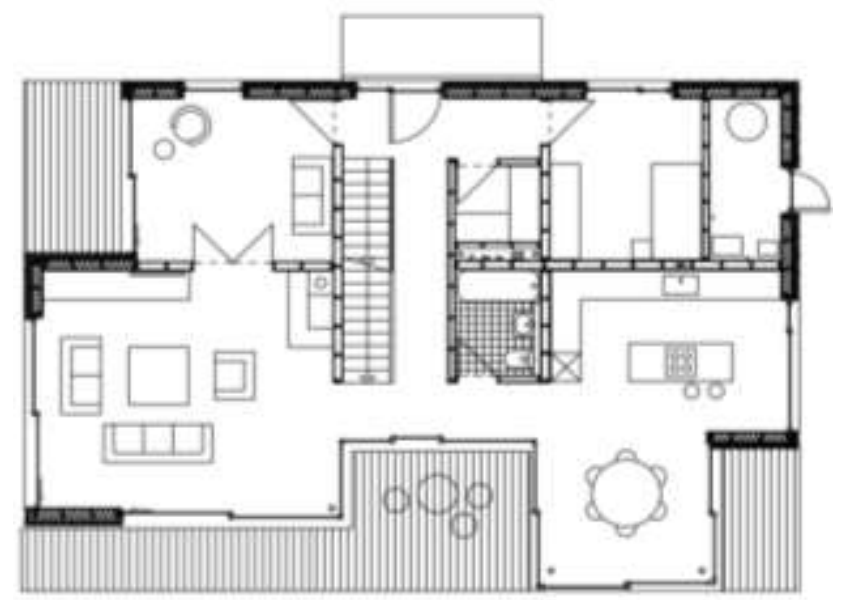

Fig. 3. Prof. M. Eichner, House 214, wooden frame construction. 
The eLCA-evaluation considered material components like main construction system, insulation, façade and inside walls, technical systems, floor and wall finishing materials and roof construction of the 2 story building (Fig.4).

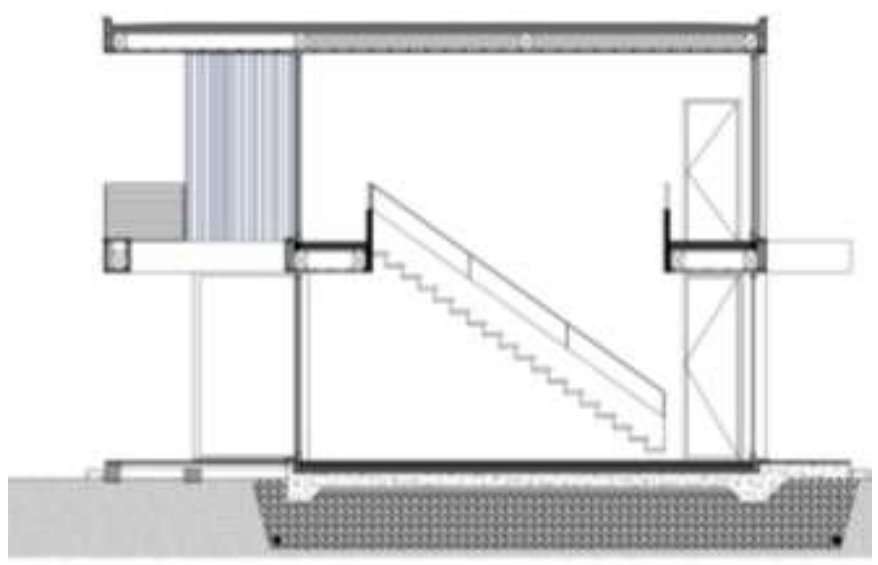

Fig. 4. Prof. Eichner, House 214, cross section, 2018

The evaluation for the Wooden frame home building showed that a building of average size for one family, using best available construction, fit-out and installation materials, heating and sanitary equipment, as it accounts to more than $16 \%$ of housing buildings in Germany or $7 \%$ of wooden single family housing buildings in Russia, cannot be considered a Nearly-Zero-Emission building and generates a significant amount of harmful greenhouse gas emissions and impacts on the global climate and environment (Fig. 5).

\begin{tabular}{|c|c|c|}
\hline indicator & unit & total $/ m^{2}$ NGFa \\
\hline GWP & $\mathrm{kg} \mathrm{CO} 2$ equiv. & 80.2852433217 \\
\hline ODP & $\mathrm{kg}$ R11 equiv. & 3.2052005593E-7 \\
\hline POCP & kg ethene equiv. & 0.0498410013 \\
\hline AP & $\mathrm{kg} \mathrm{SO} 2$ eqv. & 0.2866887516 \\
\hline EP & $\mathrm{kg} \mathrm{PO} 4$ equiv. & 0.0339916185 \\
\hline Total PE & $\mathrm{MJ}$ & $1.9578302770 \mathrm{E}^{3}$ \\
\hline PEn. ren. & $\mathrm{MJ}$ & $1.5202481122 \mathrm{E} 3$ \\
\hline PE ren. & $\mathrm{MJ}$ & 437.5821648517 \\
\hline ADP & $\mathrm{kg} \mathrm{Sb}$ equiv. & 0.6588459808 \\
\hline
\end{tabular}

Fig. 5. eLCA Overall Balance Evaluation, House 214.

Reduced material use for construction is influencing the eLCA calculation in a positive way just like renewable materials and improves the environmental impact of newly built or reconstructed buildings. The potential to reuse existing building structures or material as well as designing buildings, which can be easily disassembled and reused for the construction of new buildings, is a fundamental part of every LCA evaluation, to reduce environmental impact (Fig. 6). 


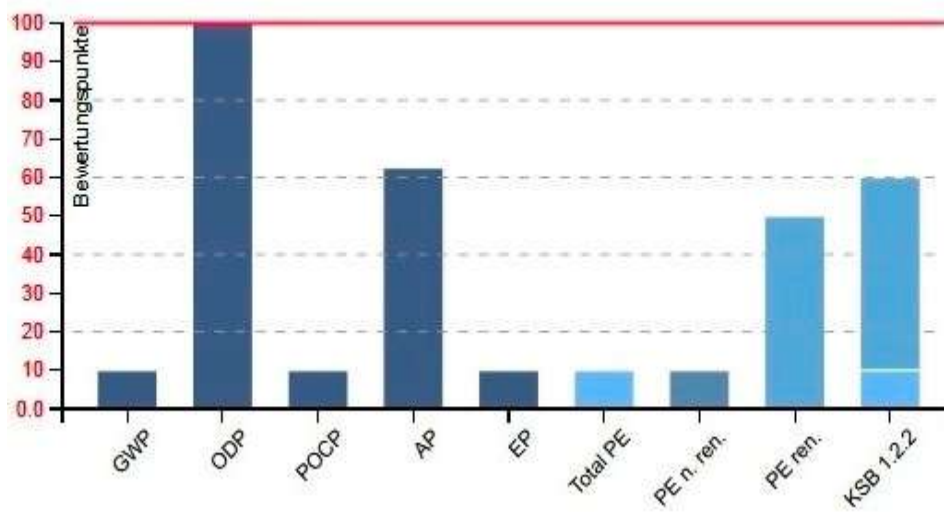

Fig. 6. eLCA Overall Benchmark Evaluation, House 214.

\section{Conclusions}

The research shows that modern family housing buildings constructed in a common wooden frame system and, as a result, low density urban districts, realized in this technology, do partly not meet minimum climate saving requirements according international sustainable standards. That is valid both for the analyzed industrial countries as well as for the developing countries of middle and Eastern Europe. The analyzed commonly built single family housing building and its low environmental friendly characteristic shows that they represent considerable risks for the global climate, the local environments. This points on the importance for further development of appropriate construction materials, instruments and building codes, to address climate saving and reduction of harmful emissions in newly built commercial and public buildings. It should be explicitly stated here that health risks for the residents were not subject of investigation as this would require additional research of different aspects.

Limiting harmful effects of construction activities for the population and the environment, global climate, and natural resources would require a significant change in construction methods, building technologies, material and energy use [12]. Sustainable building evaluation as design approach for small and large scale projects represents a realignment for the construction sector, similar to fundamental reforms currently perceived in the car industry worldwide, towards low emission and electric motorized models. The author's research project, comparing harmful emission $(\mathrm{CO} 2, \mathrm{CFC} 1, \mathrm{C} 2 \mathrm{H} 4, \mathrm{SO} 2, \mathrm{PO} 4)$ of commonly constructed housing typologies in different climatic zones and economic societies documents, that without regard to the significant differences of available technology and material availability in different countries, commonly constructed buildings do not match climate saving requirements and are not well integrated into the biosphere. More detailed future research is necessary to specify obstacles and potentials for a climate saving transformation of the built sector in different cultural and climatic areas. The authors conclude that far more effort has to be taken to meet minimum requirements for climate saving buildings.

This study was conducted with the support of the project 574049-EPP-1-2016-1-ITEPPKA2-CBHE-JP "Modernization of the Curricula in sphere of smart building engineering - Green Building (GREB), funded by the European Commission. The conclusions and opinions presented in this document reflect the viewpoint of the authors 
only, and the Commission will not bear responsibility for any use of the information contained therein.

\section{References}

1. Climate Change: Implications for Buildings, European Climate Foundation, http://www.ursa.com/en-us/news/Documents/climate_change_implications_for_ buildings_ar5_buildings_v10.pdf; http://bpie.eu/keyword/ipcc/

2. Architecture et urbanisme bioclimatique, Architecture and Climate-Friendly-Passive Town-Planning, http://vivarchi.com/spip.php?article6

3. V.A. Ilyichev, Biosphere compatibility: Technologies for introduction of innovations ("LIBROKOM", Moscow, 2011)

4. D. L. Jones, Architecture and the Environment: Bioclimatic Building Design (The Overlook Press, New York, 1998)

5. B. Givoni, Climatic Considerations in Building and Urban Design (Van Nostrand Reinhold, New York, 1998)

6. M. J. Crosbie, Green Architecture. A Guide to Sustainable Design (American Institute of Architects Press, Washington DC, 1993)

7. C. Langston, Sustainable Practices in the Built Environment (Butterworth Heinemann, Newbury, 2001)

8. B. Edwards, Green Buildings Pay (E \& FN Spon, New York, 2003).

9. A.D. Razin, Z.Sh. Alhalabi, International Research Journal 6(60), 163-165 (2017) https://research-journal.org/en/arch-en/sustainable-development-and-greenarchitecture/

10. Holzhäuser sind nachhaltig und liegen im Trend (Sebastian Doppelhammer, 2017)

11. Z. Ivanova and I. Pryadko, MATEC Web of Conferences 106 (2017) https://www.matec-conferences.org/articles/matecconf/abs/2017/20/ contents/contents.html 